Chronic Obstructive Pulmonary Diseases: Journal of the COPD Foundation

\author{
Review
}

\title{
Why is Disease Penetration so Variable in Alpha-1 Antitrypsin Deficiency? The Contribution of Environmental Factors
}

\author{
Madhu Rangaraju, MBChB, $\mathrm{MA}^{1}$ Alice M. Turner, $\mathrm{MBChB}, \mathrm{PhD}^{1,2}$
}

\begin{abstract}
Environmental influences on clinical phenotype in alpha-1 antitrypsin deficiency (AATD) include cigarette smoke, occupational exposures, airway/sputum bacteria and outdoor air pollution. This narrative review describes the impact of the major environmental exposures and summarizes their effect on clinical phenotype and outcomes. In general, patients with AATD are more susceptible to pulmonary damage as a result of the relatively unopposed action of neutrophil elastase, in the context of neutrophilic inflammation stimulated by environmental factors. However, the amount of phenotypic variability explicable by environmental factors is insufficient to account for the wide range of clinical presentations observed, suggesting that a combination of genetic and environmental factors is likely to be responsible.
\end{abstract}

Abbreviations: alpha-1 antitrypsin deficiency, AATD; chronic obstructive pulmonary disease, COPD; alpha-1 antitrypsin, AAT; neutrophil elastase, $\mathbf{N E}$; forced expiratory volume in 1 second, $\mathbf{F E V}_{\mathbf{1}}$; gas transfer coefficient, $\mathbf{K C O}$; forced vital capacity, FVC; computed tomography, $\mathbf{C T}$; diffusing capacity for carbon monoxide, DLCO; particulates with diameter < 10 $\mu$ M, PM10; Swiss Cohort Study on Air Pollution and Lung Disease in Adults, SAPALDIA; vapors, gases, dusts and fumes, VGDF; forced expiratory flow between $25 \%$ and $\mathbf{7 5} \%$ of the FVC, FEF $_{\mathbf{2 5}} \mathbf{- 7 5}$ Funding Support: This paper was funded by the Alpha-1 Foundation.

Date of Acceptance: April 24, 2020

Citation: Rangaraju M, Turner AM. Why is disease penetration so variable in alpha-1 antitrypsin deficiency? The contribution of environmental factors. Chronic Obstr Pulm Dis. 2020;7(3):280-289. doi: https://doi.org/10.15326/jcopdf.7.3.2019.0177

1 University Hospitals, Birmingham National Health Service

Foundation Trust, Birmingham, United Kingdom

2 Institute of Applied Health Research, University of Birmingham, Birmingham, United Kingdom

\section{Address correspondence to:}

Alice M. Turner, MBChB, PhD

Email: a.m.turner@bham.ac.uk

Phone +441213713885

\section{Keywords:}

alpha-1 antitrypsin deficiency; cigarette smoking; air pollution; occupational exposure; microbiota

\section{Introduction}

Alpha-1 antitrypsin deficiency (AATD) is the only widely accepted genetic risk factor for chronic obstructive pulmonary disease (COPD) and emphysema, but there is wide variability in clinical presentation. ${ }^{1}$ Many factors likely contribute to this, and interact with genetic factors in the classical "disease susceptibility + environment" manner that is common to many chronic diseases. Environmental factors are a particularly attractive area for clinicians to focus on as they are potentially modifiable, and hence influence our discussions with patients about their current exposures, and how they might alter them to minimize risk of disease. To discuss which environmental factor may be important to AATD patients, we first need to think about what our environment actually is, and which manifestations of AATD such exposures may modify. The dictionary definition of environment is "the external conditions in general affecting the life, existence, or properties of an organism or object" ${ }^{2}$; in this sense, any inhaled or ingested agent would be considered part of the environment, since it exists external to the patient, so we need to consider which of these affect pathology in AATD. 
Conceptually, social factors would also be considered part of the environment, though these are poorly studied for their relationship to pathology independent of their relationship to exposures within that environment. For example, low socio-economic status is associated with higher rates of cigarette smoking, ${ }^{3}$ and health detriments may occur from smoking, but could be influenced by other coexisting factors in the social environment. This narrative review will therefore focus on those external influences which have been studied to a reasonable degree in AATD, and affect the lungs, namely cigarette smoking, air pollution and occupation. We will then consider whether airway microbiota can be considered within the dictionary definition of environmental factors relevant to AATD or not. Finally, the environmental influences on disease outside the lungs will be discussed briefly.

\section{Effects of Cigarette Smoke}

In AATD one of the main drivers of lung pathology is protease imbalance, mediated by the relative deficiency of alpha-1 antitrypsin (AAT), and hence unopposed action of neutrophil elastase (NE) and other proteases. ${ }^{4}$ The mechanism by which this occurs is illustrated in Figure 1. Whenever a neutrophil enters the lung there is an obligate area of damage associated with the release of NE, which in AATD is larger than in individuals with normal AAT levels since it is unopposed. Smoking stimulates neutrophilic inflammation in the lung, and hence the amount of NE-mediated damage to the lung in AATD is larger than in smokers who have normal AAT levels. Once COPD is present, this also influences neutrophil transit in the lung, ${ }^{5}$ hence there is the possibility of exacerbating pathogenic processes dependent on the neutrophil, though it is possible neutrophil transit changes are exclusive to usual COPD, as in vitro work suggests PiZZ neutrophils have normal chemotactic activity. ${ }^{6}$ Aging may modify the effect of smoke exposure on neutrophilic inflammation in mice, ${ }^{7}$ and it is possible this effect exists in man, given that smoke exposure in older age appears more deleterious. ${ }^{8}$ In addition, smoke exposure may alter the inherent immunological and oxidative properties of AAT in a detrimental way, ${ }^{9,10}$ and in polymeric forms of AATD, may drive polymerization. ${ }^{10}$ Polymers themselves drive inflammation, ${ }^{11}$ hence the effects of smoking in AATD may be further magnified by a secondary accumulation of polymers.
This wealth of mechanistic data supporting harmful effects of cigarette smoke is supported by clinical observations. Patients with AATD who smoke, or have smoked, are more likely to exhibit COPD and emphysema, and the relevant physiological markers of these conditions, specifically lower forced expiratory volume in 1 second $\left(\mathrm{FEV}_{1}\right)$ and gas transfer coefficient (KCO), than those with less or no smoke exposure. ${ }^{12}$ The prevalence of chronic bronchitis appeared unrelated to smoke exposure in our data ${ }^{12,13}$; this is perhaps surprising since early onset chronic bronchitis outside AATD is associated with smoke exposure. ${ }^{14}$ The AATD genotypes have variable levels of risk dependant on enzyme levels. PiMM individuals have normal levels of AAT and thus, smoking results in the same risk of COPD as in non-AATD individuals. ${ }^{15}$ PiMZ individuals are at a slightly increased risk of emphysema, ${ }^{16}$ but do not develop lung disease in the absence of smoking ${ }^{17} ; \mathrm{FEV}_{1}$ to forced vital capacity (FVC) ratio and $\mathrm{FEV}_{1} \%$ predicted are significantly decreased compared to PiMM individuals, with a higher rate of $\mathrm{FEV}_{1}$ decline in PiMZ ever-smokers. The following discussion references studies primarily relating to people with the PiSZ and PiZZ genotypes who may develop lung disease in the absence of smoking.

Smoking also influences lung function decline, with the most marked harm coming from current cigarette use $^{18-21}$; effect sizes of current smoking have varied in the studies that reported it but are invariably damaging. The amount smoked in terms of pack years is also relevant, in that threshold effects have been reported in both American and UK data for patients with PiZZ AATD, ${ }^{18,22}$ whereby it seems that after 20 pack years there is no longer a relationship between $\mathrm{FEV}_{1}$ and exposure. In patients who are PiSZ this threshold rises to 30 pack years, ${ }^{18}$ consistent with the higher AAT levels that such patients generally have, and the known relationship between greater area of obligate NE-mediated damage and AAT level. Some caution must be exercised when considering these putative thresholds as the data from which they were generated does show marked scatter, consistent with multiple influences (both genetic and environmental) on $\mathrm{FEV}_{1}$ - indeed the amount of variability in $\mathrm{FEV}_{1}$ explicable by pack years smoked was just $15 \%$ in UK data. ${ }^{12}$ The duration of smoking may also be relevant, as data from the German registry demonstrates that longer durations associate with faster subsequent 


\title{
Figure 1. Mechanism of Damage from Neutrophilic Inflammation in the Alpha-1 Antitrypsin Deficiency Lung
}

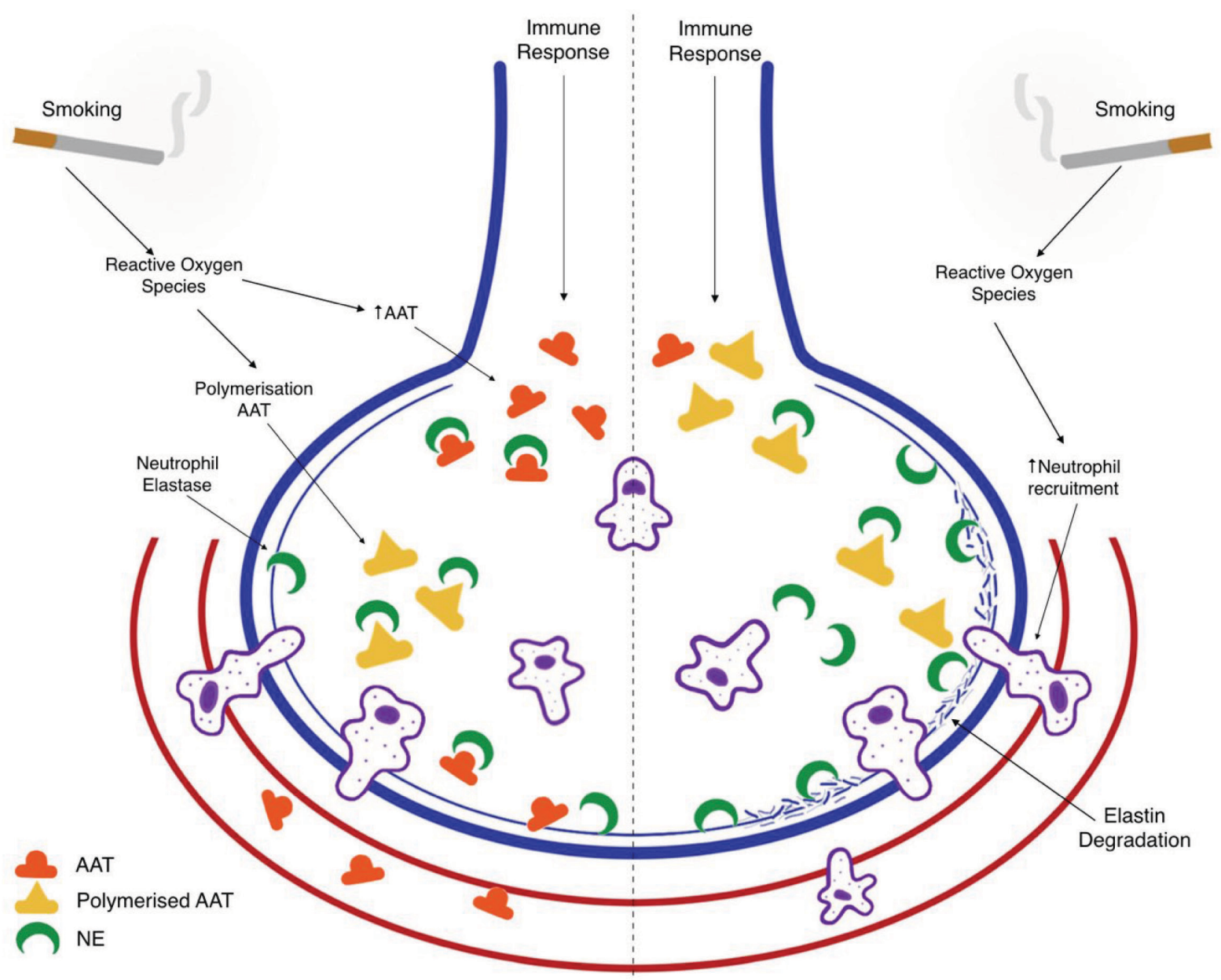

\begin{abstract}
The figure shows migration of neutrophils from the blood into the airspaces of the lung, with normal lung shown on the left and AATD on the right. Inflammation triggers normal immunological responses resulting in increased AAT release due to neutrophil recruitment and release of NE. Smoking also releases ROS, causing increased neutrophil recruitment and subsequent increase in NE and AAT. Different mutations in the SERPINA1 gene result in varying amounts of AAT deficiency. Unopposed NE action causes alveolar destruction by proteolysis resulting in emphysema. This is illustrated by the cell on the right of the figure, where diffusion of active NE outwards from the cell is greater in AATD than a PiMM individual. In addition to this protease imbalance mechanism, polymerization of AAT occurs in the presence of malformed AAT proteins and ROS. Polymerized AAT results in increased neutrophil recruitment and further alveolar inflammation. This may contribute to rapid progression of emphysematous changes in AATD patients.
\end{abstract}

$\mathrm{AATD}=$ alpha-1 antitrypsin deficiency; $\mathrm{NE}=$ neutrophil elastase; $\mathrm{AAT}=$ alpha-1 antitrypsin; $\mathrm{ROS}=$ reaction oxygen species

$\mathrm{FEV}_{1}$ decline ${ }^{23}$; teasing out the differences between cumulative exposure (pack years) from duration is clearly difficult and requires further research. Age at onset of smoke exposure may also be critical, as demonstrated by Mayer et al in a survey of patients with PiZZ AATD, which reported earlier onset of symptoms in those exposed to smoke passively in childhood. ${ }^{24}$ Passive smoke was also a risk factor for lung disease in an independent study, albeit of only 52 PiZZ patients. ${ }^{25}$ Whether age at onset is a risk independent of total amount or duration is unknown. Interestingly, data, such as that from the Swedish registry, ${ }^{26}$ has reported that after smoking cessation, $\mathrm{FEV}_{1}$ decline may return to that of a never smoker. This emphasizes the importance of smoking cessation at any time of life in patients with AATD, and perhaps suggests that the relationship between pack years smoked and FEV $\mathrm{F}_{1}$ is largely related to damage incurred during the period of active smoking.

Smoking may also relate to a higher exacerbation 
frequency, and concomitant deterioration in quality of life over time, as shown in the German registry. ${ }^{27,28}$ While relatively few studies have reported influences on exacerbations in AATD, the strong influence of smoking on exacerbation rate in COPD without AATD implies that this may be a true finding, irrespective of published replication in other cohorts.

Further research about smoking in AATD might focus on improving our understanding of specific phenotypic associations as that has been limited by lack of detailed phenotyping in many AATD cohorts internationally, in particular there have been relatively few quantitative computed tomography (CT) studies in AATD outside the context of clinical trials, when compared to usual COPD, and few studies that have data on small airways disease whether measured physiologically or radiologically. The COPD Genetic Epidemiology study emphasizes the value of CT studies on progression of emphysema and air trapping. ${ }^{29}$ Radiographic progression was found to have variable correlation to $\mathrm{FEV}_{1},{ }^{29}$ and better association to rate of diffusing capacity for carbon monoxide (DLCO) decline especially in severe disease. ${ }^{30}$ There is no data available on other inhaled smoke types, such as cannabis, heroin or other drugs of abuse, or of vaping with lung disease in AATD, but since these are known to be harmful in people with normal AAT levels, ${ }^{31}$ we can reasonably presume that they will be more harmful in AATD.

\section{Effects of Outdoor Air Pollution}

There are a number of pollutants potentially relevant to lung disease risk, of which the most important in the general COPD literature are particulate matter and ozone. Studies of outdoor air pollution in AATD have been conducted by our group in the United Kingdom in PIZZ patients and reported for PiMZ patients by a European group. In PiZZ AATD patients we found that a surrogate measure for lifelong exposure to ozone, namely current ozone level as determined by geocoding of pollution (geographical information system mapping, down to a $1 \mathrm{~km}$ level, based on the patients' home address), related to lower FEV 1 and $\mathrm{KCO}$ at time of enrollment to the cohort, ${ }^{32}$ after adjustment for cigarette smoke exposure and other relevant demographic features. The effect of ozone was relatively small, with the difference in ozone seen between urban and rural environments associating with a difference of $2 \%$ in $\mathrm{KCO}$, and overall ozone exposure accounting for $1 \%$ of $\mathrm{KCO}$ variability. AAT levels in the lung are elevated after exposure to ozone, ${ }^{33}$ and AAT offers over $80 \%$ of pulmonary defense against ozone induced inflammation. ${ }^{34}$ This suggests a rationale for enhanced susceptibility to ozone in AATD. However, the use of cross-sectional data had limitations, as was demonstrated by the data for particulates with diameter $<10 \mu \mathrm{M}$ (PM 10) where current high levels appeared to relate to better lung function. At a biological level this seemed implausible, given that particulates stimulate neutrophilic inflammation to which patients with AATD would be more vulnerable in terms of lung damage. We therefore went on to study true cumulative exposure with respect to lung function decline; while the range of values seen for lung function decline was not as wide as the range seen in baseline data for each lung function parameter (thus potentially limiting power to detect pollution effects) the model was almost certainly more robust when considering accuracy of pollution data. This study showed that PM 10 adversely affected FEV 1 decline, and ozone related to decline in $\mathrm{KCO} .{ }^{35}$ Once more, effect sizes were small, with an increase of $1 \mu \mathrm{g} /$ $\mathrm{m} 3$ in PM10 exposure relating to an additional 3ml/ year of loss in FEV 1 .

One study in the Swiss Cohort Study on Air Pollution and Lung Disease in Adults (SAPALDIA) demonstrated in short term follow (2001-2003) that PM10 exposure did not appear to interact with AATD genotype with respect to $\mathrm{FEV}_{1}$ decline, however, the only statistics generated were on PiMZ individuals in the study comparing to PiMM as the reference. ${ }^{36}$ This suggests that the effect of pollution on decline is lost in lower risk genotypes, or is so subtle as not to be detectable in a short period of follow up. This is consistent with the UK data from PiZZ patients and the concept that lower AAT levels carry corresponding increased risks from environmental insults. Confirming this, a study of a single large exposure to environmental dusts, after the collapse of the World Trade Center towers (9/11), demonstrated increased FEV 1 decline in exposed PiMZ and PiSZ firefighters relative to normal genotypes. ${ }^{37}$

\section{The Influence of Occupational Exposures}

There are a number of occupational exposures which could stimulate pulmonary inflammation, 
and hence be of greater risk to patients with PiZZ AATD compared to normal individuals. Occupational exposure is often assessed in large epidemiological studies by use of self-reported exposure to vapors, gases, dusts and fumes (VGDF), which are relevant to development of airways disease. This is an accepted method of reporting such data, but potentially less accurate in comparison to a full occupational history, whereby the job the patient did is used to assign the level of risk. This is usually done via a job exposure matrix $^{38}$ which classifies jobs for their likely level of risk using Standard Occupational Classifications ${ }^{39}$ (e.g., SOC 2000) generated using a recognized system (e.g., CASCOT). While this is more accurate, it is also much more time consuming and relies on patients remembering all the jobs they have done.

An early study in 52 PiZZ patients identified that lower $\mathrm{FEV}_{1}$ was observed in those reporting $\mathrm{VGDF}$ exposure, albeit not statistically significant $(p=0.07){ }^{25}$ More recently, exposure to VGDF (or an equivalent self-reported measure) has been assessed in AATD by Germany, Sweden, National Jewish Health and SAPALDIA studies, comprising 451 PiZZ, 6 PiSZ and 220 PiMZ participants altogether. ${ }^{23,36,40-42}$ Results of these studies are summarized in Table 1 . In general, VGDF exposure was associated with increased symptomatology, reduced lung function and lung function decline. ${ }^{23}$ In PiMZ carriers an interaction was seen between genotype, smoking and VGDF exposure such that those carrying a $Z$ allele, smoking and having VGDF exposure were more likely to exhibit deterioration in their small airways (as measured by forced expiratory flow between $25 \%$ and $75 \%$ of the FVC $\left.\left[\mathrm{FEF}_{25-75}\right]\right) .{ }^{36}$ In PiZZ patients, agricultural employment in particular was associated with lower $\mathrm{FEV}_{1}$ and increased bronchial hyperresponsiveness $(\mathrm{BHR})^{41-42}$; increased BHR was also seen in PiMZ participants but the risk was approximately half that of a PiZZ person. In addition to farmers, those in the timber industry (e.g., wood trimmers, furniture making, sawmills) are at higher risk of allergic alveolitis and lung cancer. ${ }^{43}$ While this study ${ }^{43}$ was not specific to AATD, it is probable the same or enhanced risks apply since studies have linked wood dust exposure to increased antibody secretion resulting in airway inflammation, ${ }^{44}$ which then may result in decreased $\mathrm{FEV}_{1}$ and increased $\mathrm{FEV}_{1}$ decline ${ }^{45}$ in normal individuals. In any pro-inflammatory insult like this, people with AATD are likely to be more at risk due to reduced inhibition of inflammation.

In our own data (previously published only in abstract form), ${ }^{46}$ we took a different approach, and classified occupational risk using a job exposure matrix, from the full occupational history. Data was available on 379 PiZZ patients, and risk was allocated according to likelihood of exposure to a risk agent, determined by an occupational hygienist. If the intensity was likely to be less than $30 \%$ of the workplace exposure limit this was classed as low risk, with intensities above this being deemed high risk. Those who had never worked in an exposure prone job were classed as zero risk. Patients had worked for a mean of 19 years and stopped work on average at age 48 years if cessation was due to lung disease. There were no differences in duration of working life or age when stopped work between risk groups. Characteristics of the patients are shown in Table 2; no elements of lung function differed between risk groups. While our results contradict others' data, there are several possible explanations for this; firstly, it is possible our methods were more robust and specific to occupational exposure than other selfreported studies, in which VGDF exposure might have been overestimated due to recall biases. Secondly, it is possible that the use of a general job exposure matrix rather than one specifically selecting airways disease could have influenced results; this would have been difficult to do, since many professions exposed to agents known to lead to interstitial or fibrotic disease (e.g., asbestos in building trade) also have exposure to agents known to influence airways disease (e.g., wood dusts in building trade). Thirdly, it might be that confounding was influencing results; in order to assess the latter issue we looked specifically at lung function decline according to occupational risk, adjusting for both pollution, smoke exposure and other relevant covariates, and found enhanced $\mathrm{KCO}$ decline in high risk occupations relative to those with zero risk, with enhanced $F E V_{1}$ decline also being seen in female workers in high risk jobs. ${ }^{47}$

There have been few studies of non-VGDF exposures in AATD. However, one study of asbestos exposure reported an increased risk of asbestosis in carriers of the $S$ or $Z$ allele. ${ }^{48}$ The number of patients was small, and the mechanism less clear than it would be for airways disease, so further studies of fibrotic lung diseases in AATD patients would be required to say if there is enhanced risk of pulmonary pathology outside of the airway. Notably, in our dataset reported above, 


\section{Table 1. Summary of Studies of Occupational Risk According to Alpha-1 Antitrypsin Deficiency Genotype}

\begin{tabular}{|c|c|c|c|}
\hline Reference & N \& Genotype & Exposure Type & Clinical Findings \\
\hline $\begin{array}{l}\text { Fahndrich } \\
\text { et } \mathrm{al}^{23}\end{array}$ & $\begin{array}{l}\mathrm{PiZZ} \\
\mathrm{N}=100 \mathrm{FEV}_{1} \\
\mathrm{~N}=116 \mathrm{TLCO}\end{array}$ & $\begin{array}{l}\text { - Smoking } \\
\text { - Exacerbations } \\
\text { - Occupational dusts }\end{array}$ & $\begin{array}{l}\text { - } \uparrow \mathrm{FEV}_{1} \text { decline associated with occupational dust exposure, } \\
\text { shorter duration of smoking abstinence and an increased } \\
\text { frequency of exacerbations per year. }\end{array}$ \\
\hline $\begin{array}{l}\text { Mehta } \\
\text { et } \mathrm{al}^{36}\end{array}$ & $\begin{array}{l}\mathrm{PiMZ} \\
\mathrm{N}=97\end{array}$ & $\begin{array}{l}\text { - Pollution (PM10) } \\
\text { - Occupational VGDF }\end{array}$ & $\begin{array}{l}\text { - No significant clinic findings for PM10 } \\
\text { - } \mathrm{FEF}_{25-75} \text { \& } \mathrm{FEV}_{1} / \mathrm{FVC} \text { decline in VGDF exposed } \\
\text { smokers v PiMM }\end{array}$ \\
\hline $\begin{array}{l}\text { Mayer } \\
\text { et } \mathrm{al}^{39}\end{array}$ & $\begin{array}{l}\mathrm{P} * \mathrm{ZZ} \\
\mathrm{N}=128\end{array}$ & $\begin{array}{l}\text { - Smoking } \\
\text { - Occupational dust, fumes, } \\
\text { smoke and gas }\end{array}$ & $\begin{array}{l}\text { - } \uparrow \text { mineral dust associated with cough, leaving employment } \\
\text { due to breathlessness, } \downarrow \mathrm{FEV}_{1} \text { and } \downarrow \mathrm{FEV}_{1} / \mathrm{FVC} \\
\text { - Exposure to occupational fumes or smoke associated with } \\
\downarrow \mathrm{FEV}_{1} / \mathrm{FVC} \text { ratio. }\end{array}$ \\
\hline $\begin{array}{l}\text { Piitulainen } \\
\text { et } \mathrm{al}^{41}\end{array}$ & $\begin{array}{l}\mathrm{PiZZ} \\
\mathrm{N}=205\end{array}$ & $\begin{array}{l}\text { - Agricultural work } \\
\text { - Passive smoking } \\
\text { - Indoor pollution }\end{array}$ & $\begin{array}{l}\text { - Agricultural work > } 10 \text { years associated with wheezing and } \\
\text { chronic bronchitis } \\
\text { - Exposure to kerosene heaters (not gas cookers) and } \\
\text { agricultural work associated with } \downarrow \mathrm{FEV}_{1} \% \text { \& VC } \\
\text { - Passive smoke }>10 \text { years associated with chronic bronchitis }\end{array}$ \\
\hline $\begin{array}{l}\text { Sigsgaard } \\
\text { et } \mathrm{al}^{40}\end{array}$ & $\begin{array}{l}\text { PiZZ N=2 } \\
\text { PiSZ N=6 } \\
\text { PiSS N=4 } \\
\text { PiMZ N=123 }\end{array}$ & - Farming work & $\begin{array}{l}\text { - Increased odds ratio for BHR with PiSZ, SS, ZZ alleles (4.34) } \\
\text { in farming school attendant group compared to control } \\
\text { group }\end{array}$ \\
\hline
\end{tabular}

$\mathrm{FEV}_{1}=$ forced expiratory volume in 1 second; $\mathrm{TLCO}=$ transfer factor for carbon monoxide; VGDF=vapors, gas, dusts, fumes;

$\mathrm{FVC}=$ forced vital capacity; $\mathrm{BHR}=$ bronchial hyperresponsiveness

\section{Table 2. Characteristics of PiZZ Patients Studied Using a Job Exposure Matrix}

\begin{tabular}{|c|c|c|c|c|}
\hline & \multicolumn{3}{|c|}{ Level of Occupational Risk } & \multirow{2}{*}{$p$ Value } \\
\hline & Zero & Low & High & \\
\hline Gender $\left(\%{ }^{-}\right)$ & 60.9 & 67.7 & 50.7 & ns \\
\hline Age & $50.40(0.8)$ & $48.8(1.3)$ & $49.2(1.3)$ & ns \\
\hline Pack Years & $14(0.2-26)$ & $13.5(5.3-24.5)$ & $15.8(0-24)$ & ns \\
\hline FEV 1 (\% predicted) & $36.7(25.8-58.9)$ & $39.9(24.1-68.5)$ & $34.7(25.9-69.9)$ & ns \\
\hline FEV $_{1} /$ FVC $(\%)$ & $38.2(29-53)$ & $41(30.6-57)$ & $39.1(32-60.3)$ & ns \\
\hline KCO \% Predicted & $68.9(57.4-88.8)$ & $69.9(2.8)$ & $66.1(57-85.9)$ & ns \\
\hline $\begin{array}{l}\text { Bronchodilator Reversibility } \\
\text { (\% of patients with } \\
\text { reversibility present) }\end{array}$ & 62.2 & 64.7 & 59.5 & ns \\
\hline
\end{tabular}

Bronchodilator reversibility was defined as $>12 \%$ improvement in $\mathrm{FEV}_{1}$ after administration of a nebulized bronchodilator, with an improvement which was also at least $200 \mathrm{ml}$ in volume.

$\mathrm{FEV}_{1}=$ forced expiratory volume in 1 second; $\mathrm{FVC}=$ forced vital capacity; $\mathrm{KCO}=$ gas transfer coefficient 
no participants exhibited restrictive lung function or interstitial lung disease on high-resolution CT, even though risk professions potentially linked to asbestos (e.g., construction work) were amongst the most common risk groups seen.

\section{Are Airway Bacteria a Relevant Environmental Factor?}

The presence of bacteria in the sputum or airway could be considered a relevant factor since they are acquired from the environment around us and influence clinical phenotype. Bacterial colonization of the airway may influence exacerbation rate, health status $^{49}$ and subsequent lung function decline in usual COPD, and since bacterial events involve neutrophilic inflammation, ${ }^{49,50}$ conceivably these effects would be enhanced in patients who have AATD. There is some evidence that this is the case, with exacerbating AATD patients exhibiting more inflammation than those with usual COPD, ${ }^{51}$ and those with colonization exhibiting greater immune activation, as measured by free light chain level in the blood. ${ }^{52}$ However, colonization itself may be influenced by genetic modifiers in AATD, ${ }^{53}$ implying that gene-environment interaction exists and thus it may be difficult to separate phenotypic features due to exposure to infection, from those due to underlying genetic influences.

There is growing evidence that the bacteria we culture are not the only relevant part of the microbial environment, with studies in other airway diseases demonstrating changes in inflammation ${ }^{54}$ and clinical phenotype dependent on type of micro-organisms, as measured by 16 s DNA analysis, ${ }^{55,56}$ and on outcome, specifically mortality. ${ }^{57}$ Ongoing analyses of the microbiome in AATD as part of the GRADS research programme (NCT01832220) will therefore be of interest in the future, to aid understanding of this environmental factor.

\section{Environmental Influences Influencing Disease Outside the Lung}

Since ingested substances may be considered part of the environment, it is worth noting that alcohol is a recognized co-factor in development of liver fibrosis and cirrhosis when the $\mathrm{Z}$ allele is present. ${ }^{58}$ However, unlike smoke exposure in the lung where there is a synergistic interaction between genotype and environmental exposure, the mechanism of AATD liver disease is not enhanced by alcohol, and the association is likely observed simply due to additive effects of environment and genotype. Nevertheless, AATD patients should be advised about the risks of alcohol to the liver, in order to minimize risk of longterm complications.

\section{Conclusions}

Patients with AATD have enhanced susceptibility to inflammatory stimuli in the environment, predominantly cigarette smoke, although air pollution and occupational inhalational exposures also play a part. The degree of variability in respiratory presentation accounted for by environmental factors is difficult to accurately quantify but undeniably is linked to lung disease progression in AATD patients.

\section{Declaration of Interest}

AMT has received research funding and/or honoraria from the Alpha-1 Foundation, the American Thoracic Society Foundation, Chest Foundation, National Institute for Health Research, Chiesi, AstraZeneca, CSL Behring and ResMed within the last 3 years. 


\section{References}

1. Stockley RA, Turner AM. Alpha-1 antitrypsin deficiency: clinical variability, assessment, and treatment. Trends in molecular medicine. 2014;20(2):105-115.

doi: https://doi.org/10.1016/j.molmed.2013.11.006

2. Oxford English Dictionary. Oxford: Oxford University Press; 2019. Accessed July 2020. https://www.oed.com/.

3. Allen L, Williams J, Townsend N, et al. Socioeconomic status and non-communicable disease behavioral risk factors in lowincome and lower-middle-income countries: a systematic review. Lancet Glob Health. 2017;5(3):e277-e89.

doi: https://doi.org/10.1016/S2214-109X(17)30058-X

4. Stockley RA. Neutrophils and protease/antiprotease imbalance. Am J Respir Crit Care Med. 1999;160(5 Pt 2):S49-52. doi: https://doi.org/10.1164/ajrccm.160.supplement_1.13

5. Ruparelia P, Szczepura KR, Summers C, et al. Quantification of neutrophil migration into the lungs of patients with chronic obstructive pulmonary disease. Eur J Nucl Med Mol Imaging. 2011;38(5):911-919.

doi: https://doi.org/10.1007/s00259-010-1715-7

6. Sapey E, Stockley JA, Greenwood H, et al. Behavioral and structural differences in migrating peripheral neutrophils from patients with COPD. Am J Respir Crit Care Med. 2011;183(9):1176-1186.

7. Moriyama C, Betsuyaku T, Ito Y, et al. Aging enhances susceptibility to cigarette smoke-induced inflammation through bronchiolar chemokines. Am J Respir Cell Mol Biol. 2009; 42(3):304-311. doi: https://doi.org/10.1165/rcmb.2009-0025OC

8. Kohansal R, Martinez-Camblar P, Agusti A, Buist AS, Mannino $\mathrm{DM}$, Soriano JB. The natural history of chronic airflow obstruction revisited: an analysis of the Framingham offspring cohort. Am J Respir Crit Care Med. 2009;180:3-10.

doi: https://doi.org/10.1164/rccm.200901-0047OC

9. Stockley RA, Afford SC. The immunological assessment of alpha-1 antitrypsin with reference to its function in bronchial secretions. Clin Sci (Lond). 1983;65(4):373-81.

doi: https://doi.org/10.1042/cs0650373

10. Alam S, Li Z, Janciauskiene S, Mahadeva R. Oxidation of Z alpha-1 antitrypsin by cigarette smoke induces polymerization: a novel mechanism of early-onset emphysema. Am J Respir Cell Mol Biol. 2011;45(2):261-269.

doi: https://doi.org/10.1165/rcmb.2010-03280C

11. Mahadeva R, Atkinson C, Li Z, et al. Polymers of Z alpha-1 antitrypsin co-localize with neutrophils in emphysematous alveoli and are chemotactic in vivo. Am J Pathol. 2005;166(2):377386. doi: https://doi.org/10.1016/S0002-9440(10)62261-4
12. Wood AM, Simmonds MJ, Bayley DL, Newby PR, Gough SC, Stockley RA. The TNFalpha gene relates to clinical phenotype in alpha-1-antitrypsin deficiency. Respir Res. 2008;9:52. doi: https://doi.org/10.1186/1465-9921-9-52

13. O’Brien ME, Pennycooke K, Carroll TP, et al. The impact of smoke exposure on the clinical phenotype of alpha-1 antitrypsin deficiency in Ireland: exploiting a national registry to understand a rare disease. COPD. 2015;12 (Suppl 1):2-9. doi: https://doi.org/10.3109/15412555.2015.1021913

14. Zhu L, Ni Z, Luo X, et al. The outcome and the influencing factors of the age of onset in post-mortem of chronic bronchitis patients: a retrospective study. Int J Chron Obstruct Pulmon Dis. 2018;13:645-652. doi: https://doi.org/10.2147/COPD.S157084

15. Ferrarotti I, Thun GA, Zorzetto M, et al. Serum levels and genotype distribution of alpha-1 antitrypsin in the general population. Thorax. 2012;67(8):669-674.

doi: https://doi.org/10.1136/thoraxjnl-2011-201321

16. Hersh CP, Dahl M, Ly NP, Berkey CS, Nordestgaard BG, Silverman EK. Chronic obstructive pulmonary disease in alpha-1 antitrypsin PI MZ heterozygotes: a meta-analysis. Thorax. 2004;59(10):843-849. doi: https://doi.org/10.1136/thx.2004.022541

17. Molloy K, Hersh CP, Morris VB, et al. Clarification of the risk of chronic obstructive pulmonary disease in alpha-1 antitrypsin deficiency PiMZ heterozygotes. Am J Respir Crit Care Med. 2014;189(4):419-427.

doi: https://doi.org/10.1164/rccm.201311-1984OC

18. Green CE, Vayalapra S, Hampson JA, Mukherjee D, Stockley RA, Turner AM. PiSZ alpha-1 antitrypsin deficiency (AATD): pulmonary phenotype and prognosis relative to PiZZ AATD and PiMM COPD. Thorax. 2015;70(10):939-945.

doi: https://doi.org/10.1136/thoraxjnl-2015-206906

19. Hutchison DC, Cooper D. Alpha-1 antitrypsin deficiency: smoking, decline in lung function and implications for therapeutic trials. Respir Med. 2002;96(11):872-880. doi: https://doi.org/10.1053/rmed.2002.1381

20. Seersholm N, Kok-Jensen A, Dirksen A. Decline in FEV1 among patients with severe hereditary alpha-1 antitrypsin deficiency type PiZ. Am J Respir Crit Care Med. 1995;152(6 Pt 1):1922-1925. doi: https://doi.org/10.1164/ajrccm.152.6.8520756

21. Stockley RA, Edgar RG, Pillai A, Turner AM. Individualized lung function trends in alpha-1 antitrypsin deficiency: a need for patience in order to provide patient centered management? Int J Chron Obstruct Pulmon Dis. 2016;11:1745-1756. doi: https://doi.org/10.2147/COPD.S111508

22. Castaldi PJ, DeMeo D, Kent DM, et al. Development of predictive models for airflow obstruction in alpha-1 antitrypsin deficiency. Am J Epidemiol. 2009;170:1005-1013. doi: https://oi.org/10.1093/aje/kwp216 
23. Fahndrich S, Bernhard N, Lepper PM, Vogelmeier C, Seibert M, Wagenpfeil Sea. Exacerbations and duration of smoking abstinence are associated with the annual loss of $\mathrm{FEV}_{1}$ in individuals with PiZZ alpha-1 antitrypsin deficiency. Respir Med. 2017;129:8-15. doi: https://doi.org/10.1016/j.rmed.2017.05.011

24. Mayer AS, Stoller JK, Vedal S, et al. Risk factors for symptom onset in PI*Z alpha-1 antitrypsin deficiency. Int J Chron Obstruct Pulmon Dis. 2006;1(4):485-492.

doi: https://doi.org/10.2147/copd.2006.1.4.485

25. Silverman EK, Pierce JA, Province MA, Rao DC, Campbell EJ. Variability of pulmonary function in alpha-1 antitrypsin deficiency: clinical correlates. Ann Intern Med. 1989;111(12):982991. doi: https://doi.org/10.7326/0003-4819-111-12-982

26. Hiller AM, Piitulainen E, Jehpsson L, Tanash H. Decline in FEV1 and hospitalized exacerbations in individuals with severe alpha- 1 antitrypsin deficiency. Int J Chron Obstruct Pulmon Dis. 2019;14:1975-1983. doi: https://doi.org/10.2147/COPD.S 195847

27. Bernhard N, Lepper PM, Vogelmeier C, et al. Deterioration of quality of life is associated with the exacerbation frequency in individuals with alpha-1 antitrypsin deficiency - analysis from the German Registry. Int J Chron Obstruct Pulmon Dis. 2017;12:1427-1437. doi: https://doi.org/10.2147/COPD.S130925

28. Bernhard N, Lepper PM, Vogelmeier C, et al. Intensive smoking diminishes the differences in quality of life and exacerbation frequency between the alpha- 1 antitrypsin deficiency genotypes PiZZ and PiSZ. Respir Med. 2017;130:1-8. doi: https://doi.org/10.1016/j.rmed.2017.07.004

29. Pompe E, Strand M, van Rikxoort EM, et al. Five-year progression of emphysema and air trapping at CT in smokers with and those without chronic obstructive pulmonary disease: Results from the COPDGene study. Radiology. 2020;295(1):218-126. doi: https://doi.org/10.1148/radiol.2020191429

30. Criner RN, Hatt CR, Galban CJ, et al. Relationship between diffusion capacity and small airway abnormality in COPDGene. Respir Res. 2019;20(1):269.

doi: https://doi.org/10.1186/s 12931-019-1237-1

31. Tan WC, Bourbeau J, Aaron SD, et al. The effects of marijuana smoking on lung function in older people. Eur Respir J. 2019;54(6): 1900826.

doi: https://doi.org/10.1183/13993003.00826-2019

32. Wood AM, Harrison RM, Semple S, Ayres JG, Stockley RA. Outdoor air pollution is associated with disease severity in alpha-1 antitrypsin deficiency. Eur Respir J. 2009;34(2);346-353. doi: https://doi.org/10.1183/09031936.00087908

33. Devlin RB, McDonnell WF, Becker S, et al. Time-dependent changes of inflammatory mediators in the lungs of humans exposed to $0.4 \mathrm{ppm}$ ozone for $2 \mathrm{hr}$ : a comparison of mediators found in bronchoalveolar lavage fluid 1 and $18 \mathrm{hr}$ after exposure. Toxicol Appl Pharmacol. 1996;138(1):176-185.

doi: https://doi.org/10.1006/taap.1996.0111
34. Nadziejko C, Finkelstein I, Balmes JR. Contribution of secretory leukocyte proteinase inhibitor to the antiprotease defense system of the peripheral lung: effect of ozone-induced acute inflammation. Am J Respir Crit Care Med. 1995;152(5 Pt 1):15921598. doi: https://doi.org/10.1164/ajrccm.152.5.7582300

35. Wood AM, Harrison RM, Semple S, Ayres JG, Stockley RA. Outdoor air pollution is associated with rapid decline of lung function in alpha-1 antitrypsin deficiency. Occup Environ Med. 2010;67(8):556-561.

doi: https://doi.org/10.1136/oem.2009.047589

36. Mehta AJ, Thun GA, Imboden M, et al. Interactions between SERPINA1 PiMZ genotype, occupational exposure and lung function decline. Occup Environ Med. 2014;71(4):234-240. doi: https://doi.org/10.1136/oemed-2013-101592

37. Banauch GI, Brantly M, Izbicki G, et al. Accelerated spirometric decline in New York City firefighters with alpha (1)-antitrypsin deficiency. Chest. 2010;138(5):1116-1124. doi: https://doi.org/10.1378/chest.10-0187

38. Semple SE, Dick F, Cherrie JW. Exposure assessment for a population-based case-control study combining a job-exposure matrix with interview data. Scand $J$ Work Environ Health. 2004;30(3):241-248. doi: https://doi.org/10.5271/sjweh.785

39. U.S. Bureau of Labor Statistics. Standard occupational classification. Updated 2018. Accessed July 2020. https://www. bls.gov/soc/

40. Mayer AS, Stoller JK, Bucher-Bartelson B, et al. Occupational exposure risks in individuals with $\mathrm{PI}^{*} \mathrm{Z}$ alpha (1)-antitrypsin deficiency. Am J Respir Crit Care Med. 2000;162(2 Pt 1):553-558. doi: https://doi.org/10.1164/ajrccm.162.2.9907117

41. Sigsgaard T, Brandslund I, Omland $O$, et al. $S$ and $Z$ alpha-1 antitrypsin alleles are risk factors for bronchial hyperresponsiveness in young farmers: an example of gene/ environment interaction. Eur Respir J. 2000;16(1):50-55. doi: https://doi.org/10.1034/j.1399-3003.2000.16a09.x

42. Piitulainen E, Tornling G, Eriksson S. Environmental correlates of impaired lung function in non-smokers with severe alpha-1 antitrypsin deficiency (PiZZ). Thorax. 1998;53(11):939-943. doi: https://doi.org/10.1136/thx.53.11.939

43. Vallieres E, Pintos J, Parent ME, Siemiatycki J. Occupational exposure to wood dust and risk of lung cancer in two populationbased case-control studies in Montreal, Canada. Environ Health. 2015;14:1. doi: https://doi.org/10.1186/1476-069X-14-1

44. Eduard W, Sandven P, Levy F. Serum IgG antibodies to mold spores in two Norwegian sawmill populations: relationship to respiratory and other work-related symptoms. Am J Ind Med. 1993;24(2):207-222.

doi: https://doi.org/10.1002/ajim.4700240207 
45. Dahlqvist M, Ulfvarson U. Acute effects on forced expiratory volume in one second and longitudinal change in pulmonary function among wood trimmers. Am J Ind Med. 1994;25(4):551558. doi: https://doi.org/10.1002/ajim.4700250409

46. Wood AM, Semple S, Ayres JG, Stockley RA. Occupational exposuresinAATD.EurRespirJ.2008;32(Suppl52):3825.Accessed July 2020. https://www.ers-education.org/events/internationalcongress/berlin-2008.aspx?idParent=47715.

47. Wood AM, Harrison RM, Semple S, Ayres JG, Stockley RA. Outdoor air pollution is associated with rapid decline of lung function in alpha-1-antitrypsin deficiency. Occup Environ Med. 2010;67(8):556-561.

doi: https://doi.org/10.1136/oem.2009.047589

48. Lafuente MJ, Casterad X, Laso N, et al. $\mathrm{Pi}^{*} \mathrm{~S}$ and $\mathrm{Pi}^{*} \mathrm{Z}$ alpha 1 antitrypsin polymorphism and the risk for asbestosis in occupational exposure to asbestos. Toxicol Lett. 2002;136(1):917. doi: https://doi.org/10.1016/S0378-4274(02)00283-7

49. Banerjee D, Khair OA, Honeybourne D. Impact of sputum bacteria on airway inflammation and health status in clinical stable COPD. Eur Respir J. 2004;23(5):685-691.

doi: https://doi.org/10.1183/09031936.04.00056804

50. Marin A, Monso E, Garcia M, et al. Variability and effects of bronchial colonisation in patients with moderate COPD. Eur Respir J. 2010;35(2):295-302. doi: https://doi.org/10.1183/09031936.00126808

51. Hill AT, Campbell EJ, Bayley DL, Hill SL, Stockley RA. Evidence for excessive bronchial inflammation during an acute exacerbation of chronic obstructive pulmonary disease in patients with alpha(1) antitrypsin deficiency (PiZ). Am J Respir Crit Care Med. 1999;160(6):1968-1975.

doi: https://doi.org/10.1164/ajrccm.160.6.9904097

52. Hampson JA, Stockley RA, Turner AM. Free light chains: potential biomarkers and predictor of mortality in alpha-1 antitrypsin deficiency and COPD. Respir Res. 2016;17:34. doi: https://doi.org/10.1186/s12931-016-0348-1

53. Wood AM, Bassford C, Webster D, , et al. Vitamin D-binding protein contributes to COPD by activation of alveolar macrophages. Thorax. 2011;66(3):205-210. doi: https://doi.org/10.1136/thx.2010.140921

54. Wang Z, Bafadhel M, Haldar K, et al. Lung microbiome dynamics in COPD exacerbations. Eur Respir J. 2016;47(4):1082-1092. doi: https://doi.org/10.1183/13993003.01406-2015

55. Erb-Downward JR, Thompson DL, Han MK, et al. Analysis of the lung microbiome in the "healthy" smoker and in COPD. PLoS One. 2011;6(2):e16384. doi: https://doi.org/10.1371/journal.pone.0016384

56. Hilty M, Burke C, Pedro H, et al. Disordered microbial communities in asthmatic airways. PLoS One. 2010;5(1):e8578. doi: https://doi.org/10.1371/journal.pone.0008578
57. Rodrigo-Troyano A, Suarez-Cuartin G, Peiro M, et al. Pseudomonas aeruginosa resistance patterns and clinical outcomes in hospitalized exacerbations of COPD. Respirology. 2016;21(7):1235-1242. doi: https://doi.org/10.1111/resp.12825

58. Regev A, Guaqueta C, Molina EG, et al. Does the heterozygous state of alpha-1 antitrypsin deficiency have a role in chronic liver diseases? Interim results of a large case-control study. $J$ Pediatr Gastroenterol Nutr. 2006;43 (Suppl 1):S30-35. doi: https://doi.org/10.1097/01.mpg.0000226387.56612.1e 